Disclosure of Interests: Christine Xu Shareholder of: Sanofi, Employee of: Sanofi, Patrick Nolain Shareholder of: Sanofi, Employee of: Sanofi, Qiang Lu Shareholder of: Sanofi, Employee of: Sanofi, Anne Paccaly Shareholder of: Regeneron, Amgen, Employee of: Regeneron, Sanofi, Amgen, Melitza Iglesias-Rodriguez Shareholder of: Sanofi Genzyme, Employee of: Sanofi Genzyme, Gregory St John Shareholder of: Regeneron Pharmaceuticals Inc, Employee of: Regeneron Pharmaceuticals Inc, Chad Nivens Shareholder of: Regeneron, Employee of: Regeneron, Rafael Maldonado Grant/research support from: Sanofi, Esteve, Almirall, GSK, Boehringer, Lundbeck, Grünenthal, UPSA, Uphjon, Uriach, Ferrer, Janus, Aelis, Spherium, Pharmaleads, BRAINco, Phytoplant, Rhodes and GW Pharma., Consultant for: Sanofi, Esteve, Almirall, GSK, Boehringer, Lundbeck, Grünenthal, UPSA, Uphjon, Uriach, Ferrer, Janus, Aelis, Spherium, Pharmaleads, BRAINco, Phytoplant, Rhodes and GW Pharma., Tomonori Ishii Grant/research support from: GSK, Janssen, Consultant for: GSK, Janssen, Speakers bureau: Mitsubishi-Tanabe, Janssen, Chugai, Ono, Sanofi, Abbvie, Eisai, Astellas, UCB, Teijin, Daiichi-Sankyo, Pfizer, Takeda, Asahi, and Kasei Pharma, Ernest Choy Grant/research support from: Amgen, Bio-Cancer, Chugai Pharma, Ferring Pharmaceuticals, Novimmune, Pfizer, Roche, and Union Chimique Belge, Consultant for: Abbvie, Amgen, AstraZeneca, Biogen, BMS, Boehringer Ingelheim, Celgene, Chelsea Therapeutics, Chugai Pharma, Daiichi Sankyo, Eli Lilly, Ferring Pharmacuetical, GlaxoSmithKline, Hospita, ISIS, Jazz Pharmaceuticals, Janssen, Medlmmune, Merrimack Pharmaceutical, Merck Sharp \& Dohme, Napp, Novimmune, Novartis, ObsEva, Pfizer, Regeneron, Roche, R-Pharm, SynAct Pharma, Sanofi-Genzyme, Tonix and Union Chimique Belge, Speakers bureau: Amgen, BMS, Boehringer Ingelheim, Chugai Pharma, Eli Lilly, Hospira, Merck Sharp \& Dohme, Novartis, Pfizer, Regeneron, Roche, Sanofi-Aventis, and Union Chimique Belge, Vanaja Kanamaluru Shareholder of: Sanofi, Employee of: Sanofi

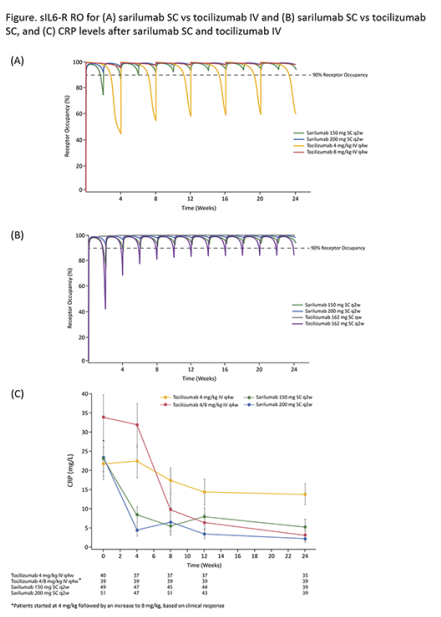

DOI: 10.1136/annrheumdis-2019-eular.3324

\begin{tabular}{|l|l}
\hline FRI0107 & THE EFFECT OF CO-MEDICATION WITH \\
METHOTREXATE OR OTHER CONVENTIONAL \\
SYNTHETIC DISEASE MODIFYING ANTI-RHEUMATIC \\
DRUGS ON FIRST TUMOR NECROSIS INHIBITOR DRUG \\
SURVIVAL IN PATIENTS WITH RHEUMATOID \\
ARTHRITIS: DATA FROM THE CZECH ATTRA REGISTRY
\end{tabular}

Heřman Mann ${ }^{1}$, Lucie Nekvindova ${ }^{2}$, Jakub Zavada ${ }^{1}$, Ladislav Šenolt ${ }^{1}$, Pavel Horak ${ }^{3}$, Zlatuse Kristkova ${ }^{2}$, Jiři Vencovský ${ }^{1}$, Karel Pavelka ${ }^{1} .{ }^{1}$ Institute of Rheumatology and Department of Rheumatology, 1st Faculty of Medicine, Charles University, Prague, Czech Republic; ${ }^{2}$ Institute of Biostatistics and Analyses, Ltd., spinoff company of Masaryk University, Brno, Czech Republic; ${ }^{3}$ IIIrd Department of internal Medicine, Faculty of Medicine and Dentistry, Palacký University Olomouc, Olomouc, Czech Republic

Background: Tumor necrosis factor inhibitors (TNFi) should be used for the treatment of rheumatoid arthritis (RA) in combination with conventional synthetic disease modifying anti-rheumatic drugs (csDMARD), preferably methotrexate (MTX). However a significant proportion of RA patients receive TNFi in combination with other csDMARD or in monotherapy.

Objectives: To assess the effect of co-medication with MTX or other csDMARDs on drug survival of TNFi treated RA patients.

Methods: All adult patients with RA followed in the Czech national regis try ATTRA who started TNFi therapy after January 1st 2012 were consid ered. Six-year drug survival for patients on TNFi in combination with MTX, with other csDMARD or in monotherapy was analyzed using Kaplan-Meier method, log rank test was used to compare differences between groups. Reasons for TNFi discontinuation were analyzed. ATTRA is a centralized prospective computerized registry of patients receiving biologic disease modifying anti-rheumatic drugs (bDMARD) therapy for rheumatic diseases collecting data on efficacy, safety and quality of life of all patients treated with bDMARDs in the Czech Republic. TNFi therapy is indicated for patients with RA who have failed treatment with at least one csDMARD.

Results: A total of 1841 RA patients initiated first bDMARD treatment during the studied period, with 1724 patients receiving TNFi. 1307 patients $(76 \%)$ started TNFi therapy in combination with MTX, 267 patients $(15 \%)$ with other csDMARD and 150 patients $(9 \%)$ as monotherapy. Overall unadjusted TNFi drug survival was better in patients receiving MTX co-medication (median survival 53 months) compared to those receiving other csDMARD (median survival 36 months) or those being on monotherapy (median survival 21 months; $p<0.001$ for monotherapy vs MTX co-medication) (Figure). The most common reason for TNFi discontinuation was loss of efficacy $(33 \%, 37 \%$ and $28 \%$ for MTX csDMARD combination and monotherapy respectively) followed by primary inefficacy $(20 \%, 19 \%$ and $27 \%)$ and adverse events $(19 \%, 15 \%$, $23 \%$ ).

Conclusion: In this registry study of patients with RA, use of MTX comedication was associated with significantly better first TNFi drug survival compared to other csDMARD co-medication and to monotherapy.

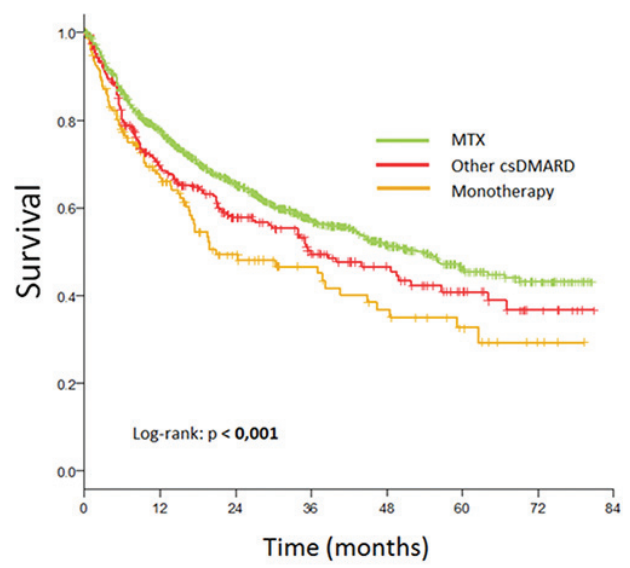

\begin{tabular}{|c|c|c|c|c|c|c|}
\hline \multicolumn{7}{|c|}{ Number of patients at risk: } \\
\hline - 1307 & 850 & 552 & 335 & 179 & 81 & 38 \\
\hline 267 & 156 & 99 & 62 & 43 & 25 & 10 \\
\hline 150 & 78 & 42 & 29 & 21 & 11 & 4 \\
\hline
\end{tabular}

Figure. Kaplan-Meier curves of 6-year drug survival of the first TNFi based on comedication

Acknowledgement: This study was supported by the project of MHCR for conceptual development of research organization 00023728

Disclosure of Interests: Heřman Mann Consultant for: Pfizer, Eli Lilly, Sanofi, Speakers bureau: AbbVie, Roche, Pfizer, MSD, Eli Lilly, Sanofi, Lucie Nekvindova: None declared, Jakub Zavada Consultant for: Genzyme-Sanofi, Glaxo, Pfizer, Abbvie, Speakers bureau: Novartis, Sandoz, Biogen, Ladislav Šenolt Grant/research support from: AbbVie, Consultant for: AbbVie, Bristol-Myers Squibb, Celgene Corporation, Merck Sharp and Dohme, Novartis, Pfizer, Roche, UCB, Amgen, Takeda, Speakers bureau: AbbVie, Amgen, Bristol-Myers Squibb, Celgene Corporation, Eli Lilly, Merck Sharp and Dohme, Novartis, Pfizer, Roche, UCB, Pavel Horak Speakers bureau: AbbVie, Roche, Pfizer, MSD, Amgen, Novartis, Eli Lilly, Sanofi. 
Zlatuse Kristkova: None declared, Jiří Vencovský Consultant for: Samsung, Speakers bureau: AbbVie, Novartis, Pfizer, Sanofi, Eli Lilly, Biogen, UCB, MSD, Werfen, Roche, Karel Pavelka: None declared DOI: 10.1136/annrheumdis-2019-eular.3973

\section{FRI0108 SHORT-TERM EFFICACY OF BCD-089, NOVEL MONOCLONAL ANTI-IL-6 RECEPTOR ANTIBODY, IN COMBINATION WITH METHOTREXATE IN PATIENTS WITH RHEUMATOID ARTHRITIS: 12-WEEK RESULTS OF PHASE 2 AURORA STUDY}

V Mazurov ${ }^{1}$, Evgeniy Zotkin ${ }^{2}$, Elena llivanova ${ }^{3}$, Tatyana Kropotina ${ }^{4}$, Tatyana Plaksina ${ }^{5}$, Olga Nesmeyanova ${ }^{6}$, Nikolaj Soroka ${ }^{7}$, Alena Kundzer ${ }^{8}$, Anton Lutskii ${ }^{9}$, Ekaterina Dokukina ${ }^{9}$, Ekaterina Chernyaeva ${ }^{9}$, Roman Ivanov ${ }^{9}$ ${ }^{1}$ North-Western State Medical University, St-Petersburg, Russian Federation; ${ }^{2}$ Nasonova Research Institute of Rheumatology, Moscow, Russian Federation; ${ }^{3}$ Leningrad Region Clinical Hospital, St-Petersburg, Russian Federation; ${ }^{4}$ Regional Clinical Hospital, Omsk, Russian Federation; ${ }^{5}$ Nizhny Novgorod Regional Clinical Hospital, Nizhny Novgorod, Russian Federation; ${ }^{6}$ Regional Clinical Hospital, Chelyabinsk, Russian Federation; ${ }^{7}$ Scientific and Practical Center of Surgery, Transplantology and Hematology, Minsk, Belarus; ${ }^{8} \mathrm{Healthcare}$ Institution Municipal Clinical Hospital, Minsk, Belarus; ${ }^{9} \mathrm{JSC}$ BIOCAD, St-Petersburg, Russian Federation

Background: In the previous phase 1 study BCD-089 (INN: levilimab) was well-tolerated, had favorable safety profile and low immunogenicity ${ }^{1}$. Here we report 12-week efficacy and safety results of ongoing phase 2 clinical study of BCD-089 in patients with active RA.

Objectives: This study is aimed to assess efficacy and safety of 2 dosing regimens of BCD-089 in patients with MTX-IR active RA.

Methods: During this multicenter double-blind placebo-controlled randomized clinical study (NCT03455842) 105 MTX-IR patients with active RA (ACR2010) were assigned (1:1:1) to receive $162 \mathrm{mg}$ of BCD-089 s.c. (QW arm and Q2W arm) or PBO. MTX (10-25 mg/week) was used in all groups. After completion of 12-week blinded period patients from QW/ Q2W arms continued the treatment, patients from PBO arm were switched to BCD-089 Q2W until Wk56. The primary efficacy endpoint was the rate of ACR20 at Wk12. Secondary endpoints included ACR50/ 70 and DAS28-CRP(4). The safety was routinely evaluated.

Results: The efficacy analysis showed that $95 \%$ confidence interval for BCD-089 treatment effect relative to PBO was [38.45 - 81.55] for QW arm and [16.53 - 63.4] for Q2W arm, which confirms the superiority to PBO of either dosing regimens. Summary of efficacy results is presented in table 1.

The majority of adverse events (AE) were laboratory abnormalities. The spectrum of AEs is similar to other IL6R inhibitors (Table 2). Three serious $A E$ (SAEs) were reported: community-acquired pneumonia ( $Q W$ arm, treatment-related), acute cholecystitis (PBO arm, not related, did not lead to treatment discontinuation), and acute heart failure leading to death (Q2W arm, not related). One case of moderate local reaction (erythema) was reported in QW arm.

Conclusion: BCD-089 in combination with MTX had superior efficacy compared with MTX plus PBO in MTX-IR patients with active RA. BCD089 showed safety profile consistent with other IL6R inhibitors. Further clinical studies are needed.

\section{REFERENCE:}

[1] Khlyabova P, et al. doi: 10.1136/annrheumdis-2018-eular.2410

Table 1. Safety results (full analysis set), $\mathrm{n}(\%)$

\begin{tabular}{lcccc}
\hline $\begin{array}{l}\text { Efficacy } \\
\text { parameter }\end{array}$ & $\begin{array}{c}\text { BCD-089 QW+MTX } \\
(\mathbf{n}=35)\end{array}$ & $\begin{array}{c}\text { BCD-089 Q2W+MTX } \\
(\mathbf{n}=35)\end{array}$ & $\begin{array}{c}\text { PBO } \\
\mathbf{+ M T X} \\
(\mathbf{n}=35)\end{array}$ & $\begin{array}{c}\text { p-value } \\
\text { (Fisher's exact } \\
\text { test })\end{array}$ \\
\hline ACR20 & $27(77.1 \%)$ & $20(57.1 \%)$ & 6 & $<0.0001$ \\
& & $11(31.4 \%)$ & $2(17.1 \%)$ & \\
ACR50 & $18(51.4 \%)$ & $7(20.0 \%)$ & $1(2.9 \%)$ & 0.0001 \\
ACR70 & $10(28.6 \%)$ & $10(28.6 \%)$ & $1(2.9 \%)$ & $<0.00601$ \\
DAS28-CRP(4) & $20(57.1 \%)$ & & &
\end{tabular}

$<3.2$

Table 2. Safety results (full analysis set), $\mathrm{n}(\%)$

\begin{tabular}{lccc}
\hline Safety parameter & $\begin{array}{c}\mathbf{B C D}-\mathbf{0 8 9} \mathbf{Q W + M T X} \\
(\mathbf{n}=\mathbf{3 5})\end{array}$ & $\begin{array}{c}\mathbf{B C D}-\mathbf{0 8 9} \mathbf{Q 2 W + M T X} \\
(\mathbf{n}=\mathbf{3 5})\end{array}$ & $\begin{array}{c}\mathbf{P B O + M T X} \\
(\mathbf{n}=\mathbf{3 5})\end{array}$ \\
\hline Any AE & $26(74.29 \%)$ & $23(65.71 \%)$ & $14(40.0 \%)$ \\
Any SAE & $1(2.86 \%)$ & $1(2.86 \%)$ & $1(2.86 \%)$ \\
Any grade 3-4 AE & $10(28.57 \%)$ & $6(17.14 \%)$ & $2(5.71 \%)$
\end{tabular}

\begin{tabular}{lccc} 
Grade 3-4 Neutropenia & $3(8.57 \%)$ & $3(8.57 \%)$ & $0(0.00 \%)$ \\
AE of special interest & & & \\
ALT/AST increased & $4(11.43 \%)$ & $5(14.29 \%)$ & $1(2.86 \%)$ \\
Leucopenia/Neutropenia & $5(14.29 \%)$ & $6(17.14 \%)$ & $1(2.86 \%)$ \\
Infections and infestations & $2(5.71 \%)$ & $1(2.86 \%)$ & $2(5.71 \%)$ \\
Total cholesterol increased & $8(22.86 \%)$ & $8(22.86 \%)$ & $2(5.71 \%)$ \\
AEs leading to treatment & $0(0.00 \%)$ & $1(2.86 \%)$ & $0(0.00 \%)$ \\
discontinuation & & & \\
Deaths & $0(0.00 \%)$ & $1(2.86 \%)$ & $0(0.00 \%)$ \\
\hline
\end{tabular}

Disclosure of Interests: V Mazurov Grant/research support from: JSC BIOCAD, Evgeniy Zotkin: None declared, Elena llivanova Grant/research support from: JSC BIOCAD, Tatyana Kropotina Grant/research support from: JSC BIOCAD, Tatyana Plaksina Grant/research support from: JSC BIOCAD, Olga Nesmeyanova Grant/research support from: JSC BIOCAD Nikolaj Soroka: None declared, Alena Kundzer: None declared, Anton Lutskii Employee of: JSC BIOCAD, Ekaterina Dokukina Employee of: JSC BIOCAD, Ekaterina Chernyaeva Employee of: JSC BIOCAD, Roman Ivanov Employee of: JSC BIOCAD

DOI: 10.1136/annrheumdis-2019-eular.7220

\section{FRI0109 EFFECTIVENESS AND SAFETY OF INFLIXIMAB, GOLIMUMAB AND GOLIMUMAB-IV IN RHEUMATOID ARTHRITIS PATIENTS FROM A PROSPECTIVE OBSERVATIONAL REGISTRY}

Proton Rahman ${ }^{1}$, Philip Baer ${ }^{2}$, Denis Choquette ${ }^{3}$, Rafat Faraawi ${ }^{4}$, Louis Bessette ${ }^{5}$, Milton Baker ${ }^{6}$, Raman Rai ${ }^{7}$, John Kelsall ${ }^{8}$, Larissa Lisnevskaia ${ }^{9}$, Jodie Reis $^{10}$, Keltie Anderson ${ }^{10}$, Wojciech Olszynski ${ }^{10}$, Emmanouil Rampakakis ${ }^{11}$, Odalis Asin Miilan ${ }^{11}$, Allen Lehman ${ }^{11}$, Meagan Rachich ${ }^{12}$, Francois Nantel ${ }^{11}{ }^{11}{ }^{1}$ Memorial University of Newfoundland, St. John's, Canada; ${ }^{2}$ Ontario Rheumatology Association, Aurora, Canada: ${ }^{3}$ Université de Montréal, Montréal, Canada; ${ }^{4}$ McMaster University, Hamilton, Canada; ${ }^{5}$ Laval University, Quebec City, Canada; ${ }^{6}$ University of Alberta, Edmonton, Canada; ${ }^{7}$ Charlton Health, Hamilton, Canada; ${ }^{8}$ University of British Columbia, Vancouver, Canada; ${ }^{9}$ Oshawa Clinic, Oshawa, Canada; ${ }^{10}$ University of Saskatchewan, Saskatoon, Canada; ${ }^{11}$ Janssen Inc, Toronto, Canada; ${ }^{12}$ Janssen Inc., Toronto, Canada

Background: Long-term registries are essential to evaluate new therapies in a patient population that differs from clinical trials and usually varies over time.

Objectives: To describe the profile of rheumatoid arthritis (RA) patients treated with infliximab (IFX), golimumab subcutaneous (GLM) or intravenous (GLM-IV) in Canadian routine care, along with its effectiveness and safety.

Methods: 1577 RA patients treated with IFX, GLM or GLM-IV were enrolled into the Biologic Treatment Registry Across Canada (BioTRAC) between 2006-2015, 2010-2017 and 2014-2017, respectively. Study visits occurred at baseline and every 6 months thereafter. Effectiveness was assessed with changes in TJC28, SJC28, MDGA, PtGA, pain, HAQ, and acute phase reactants. Safety was evaluated with the incidence of adverse events (AEs) and drug survival.

Results: Of the 890 IFX-, 530 GLM- and 157 GLM-IV-treated patients, the proportion of females were $75.7 \%-77.1 \%$, the mean age were 55.8 57.7 and the mean disease duration were 6.5-8.6 years. Most patients were bio-naive $(>80 \%)$.

A significant decrease in disease duration and disease activity scores (DAS, TJC, SJC, HAQ, AM stiffness, MDGA, PtGA, CRP, ESR) were observed in the IFX cohort over time $(p<0.001)$. Interestingly, baseline disease duration and disease activity scores for the GLM cohort (DAS, TJC, SJC, PtGA, Pain, CRP, ESR) were higher than in the IFX cohort from 2010-2012 when GLM was first introduced while the mean MDGA remained the same between the two groups.

Treatment with IFX, GLM and GLM-IV significantly improved all disease parameters over time $(P<0.001)$ from baseline to 6 months and up to 120,78 and 42 months, respectively. The proportion of patients in SDAI remission at 12, 24 and 36 months reached $16.2 \%, 20.8 \%$ and $22.8 \%$ in IFX-patients; $34.7 \%, 47.5 \%$ and $52.7 \%$ in GLM-patients and $33.8 \%$, $47.5 \%$ and $61.9 \%$ in GLM-IV-patients ( $p=0.1978$ and $p=0.0081$ vs IFX). AEs were reported for $61.5 \%, 67.4 \%$ and $59.2 \%(105,113$ and 82.6 events/100 PYs) and SAEs for $21.2 \%, 15.5 \%$ and $3.8 \%$ (11.7, 34.4 and 9.0 events/100 PYs) covering 2714, 1077 and 257 years of exposure for IFX, GLM and GLM-IV-treated patients, respectively. The most frequently occurring AEs were arthralgia and upper respiratory tract infection $(>5 \%)$. Eighteen, 7 and 1 deaths occurred among IFX-, GLM- and GLM-IVtreated patients, respectively. The proportion of patients who discontinued treatment were $74.0 \%$ over a mean 3.0 years of exposure to IFX-, 